Check for updates

Cite this: Chem. Commun., 2020, 56, 10159

Received 22nd May 2020,

Accepted 3rd July 2020

DOI: $10.1039 / \mathrm{dOcc03647a}$

rsc.li/chemcomm

\section{Isolated zirconium centres captured from aqueous solution: the structure of zirconium mandelate revealed from NMR crystallography $\dagger$}

\author{
James M. Crosland, ${ }^{a}$ Emily K. Corlett, ${ }^{b}$ Dave Scapens, ${ }^{c}$ Nathalie Guillou, ${ }^{d}$ \\ Steven P. Brown (D) ${ }^{b}$ and Richard I. Walton (D) *a
}

\begin{abstract}
Zirconium tetramandelate (2-hydroxy-2-phenylacetate) has been used for selective gravimetric analysis of zirconium for over 70 years. Herein its crystal structure is reported from synchrotron powder X-ray diffraction and ${ }^{13} \mathrm{C}$ solid-state NMR. The complex is a rare example of isolated zirconium cations, rather than the clusters prevalent in aqueous solutions.
\end{abstract}

In 1947, Kumins reported the precipitation of zirconium by mandelic acid (2-hydroxy-2-phenylacetic acid) ${ }^{1}$ and most importantly, this was in the presence of a number of other metal cations, meaning it could be used as a selective and quantitative gravimetric analysis reagent for zirconium. Alternative methods of separation or determination of zirconium content include spectrophotometrically, using alizarin, ${ }^{2,3}$ or with other gravimetric reagents such as 8-hydroxyquinoline, ${ }^{4}$ or the first to be reported, cupferron. ${ }^{5}$ Kumins' method arguably has become the most commonly used, subject to various improvements over time. ${ }^{6-9}$ The affinity of mandelic acid for zirconium is such that it can selectively operate in the presence of a range of other metal cations in solution including titanium, iron, vanadium, aluminium, chromium, thorium, cerium, tin, barium, calcium, copper, bismuth, antimony and cadmium. ${ }^{1}$ Kumins proposed that zirconium mandelate was most likely a tetramandelate, a simple salt containing four anions per zirconium atom: $\mathrm{Zr}\left(\mathrm{C}_{6} \mathrm{H}_{5} \mathrm{CH}(\mathrm{OH}) \mathrm{CO}_{2} \mathrm{H}\right)_{4}$, but its crystal structure has never been determined.

A number of other authors expanded on Kumins' work; Hahn found that the method was still applicable in strongly

\footnotetext{
${ }^{a}$ Department of Chemistry, University of Warwick, Coventry, CV4 7AL, UK. E-mail: r.i.walton@warwick.ac.uk

${ }^{b}$ Department of Physics, University of Warwick, Coventry, CV4 7AL, UK

${ }^{c}$ Luxfer MEL Technologies, Swinton, Manchester, M27 8LN, UK

${ }^{d}$ Institut Lavoisier, UMR CNRS 8180, Université de Versailles

St-Quentin-en-Yvelines, Université Paris-Saclay, 78035 Versailles, France

$\dagger$ Electronic supplementary information (ESI) available: Full experimental details and further characterisation data. CCDC 2004875. For ESI and crystallographic data in CIF or other electronic format see DOI: 10.1039/d0cc03647a
}

acidic solution, and that hafnium was also precipitated by mandelic acid. ${ }^{10}$ Feigl proposed a chelate-type structure whereby coordination of mandelate to zirconium took place through the $\alpha$-hydroxy oxygen and the acidic carboxylate oxygen, ${ }^{11}$ an idea later confirmed by Hahn and Weber. ${ }^{12}$ It was subsequently found that the use of strongly acidic conditions is key in ensuring the formation of the tetramandelate; otherwise other compositions such as $\mathrm{Zr}(\mathrm{OH})\left(\mathrm{C}_{6} \mathrm{H}_{5} \mathrm{CH}(\mathrm{OH}) \mathrm{CO}_{2} \mathrm{H}\right)_{3}$ result. ${ }^{13,14}$ In contrast to the idea of a simple $\mathrm{ML}_{4}$ complex, Larsen and Homeier formed the hypothesis that zirconium tetramandelate is in fact polymeric, despite the use of concentrated hydrochloric acid during synthesis that would solubilise $\mathrm{Zr}^{4+} \cdot{ }^{15}$ This is consistent with the oxophilic nature of zirconium and its propensity for hydrolysis in aqueous solution. ${ }^{16}$ Indeed, the most studied solution species are based upon the so-called zirconium tetramer, a slightly distorted square array of zirconium atoms linked together by double hydroxy bridges. Such an arrangement was first found to be the basis of the structure of solid zirconium oxychloride, ${ }^{17}$ and then later found to also exist in aqueous solution..$^{18}$ It is common in the solid state to find zirconium intricately linked with oxygen in chains or clusters, for example, the $\left[\mathrm{Zr}_{6} \mathrm{O}_{4}(\mathrm{OH})_{4}\right]$ octahedral clusters that form part of the structure of the archetypal metalorganic framework (MOF) UiO-66, ${ }^{19}$ and in other materials may also be present in individual clusters capped by carboxylate ligands. ${ }^{20,21}$ Chains featuring oxygen and anion-linked zirconium atoms can be found in the layered structures of the hydrated zirconium sulfates and nitrates. ${ }^{22-24}$ Chains of edge-sharing $\mathrm{ZrO}_{7}$ polyhedra are found in the structure of the MOF MIL-140, ${ }^{25}$ and chains of edge-shared $\mathrm{ZrO}_{8}$ units commonly feature in MOFs with phenolate linkers. ${ }^{26}$ Herein we present the synthesis and structural characterisation of zirconium tetramandelate, which presents the uncommon situation of isolated zirconium centres.

The reaction between zirconium salts and mandelic acid in acidic aqueous solution is rapid and produces a white crystalline solid. We tested a number of approaches to producing zirconium mandelate, including varying reaction temperature, the stereochemical form of the mandelic acid used and the 
choice of zirconium salt precursor. In all cases, the mandelic acid was present in slight excess, a $4.5 \times$ molar ratio relative to zirconium, and the reaction medium was a 9:1 mix of deionised water and 35\% hydrochloric acid, respectively, in an attempt to prohibit the formation of condensed zirconium species by hydrolysis. Solid reagents were added to a Teflon ${ }^{\mathrm{TM}}$ lined autoclave, followed by the hydrochloric acid solution and stirred magnetically for 20 minutes. The autoclave was then heated in an oven at $90{ }^{\circ} \mathrm{C}$ for 18 hours and allowed to cool slowly $\left(1^{\circ} \mathrm{C} \mathrm{min}^{-1}\right)$ to room temperature. The most crystalline product was made from zirconium sulfate tetrahydrate and $(R)$-mandelic acid (Fig. S1 and S2, ESI $\dagger$ ). It was observed that the initial precipitation of solid when using the sulfate was delayed compared to with other zirconium precursors such as zirconium oxychloride and zirconium acetylacetonate, suggesting a kinetic effect in the solution formation of the salt, possibly a reason for the increased quality of the product. Higher reaction temperatures resulted in decomposition of the mandelic acid and no crystalline product. The resulting solid was collected by vacuum filtration and washed with deionised water and acetone, and then dried at $75{ }^{\circ} \mathrm{C}$ in air before further study.

Initial characterisation by thermogravimetric analysis (Fig. S3, ESI $\dagger$ ) confirmed the number of mandelate ligands per each zirconium cation to be 4 . Fourier-transform infrared spectroscopy (Fig. S4, ESI $\dagger$ ) showed that bands relating to the $\alpha-\mathrm{O}-\mathrm{H}$ stretch ${ }^{27}$ at $3438 \mathrm{~cm}^{-1}$, and that for the free carbonyl $\mathrm{C}=\mathrm{O}$ stretch at $1712 \mathrm{~cm}^{-1}$ as seen in the spectrum for mandelic acid, were absent for the zirconium mandelate product. A very broad band possibly from the coordinated $\alpha-\mathrm{OH}$ was seen in the product spectrum centred at $3392 \mathrm{~cm}^{-1}$, and the presence of a pair of $\mathrm{C}=\mathrm{O}$ stretches at $\sim 1579 \mathrm{~cm}^{-1}$ and $\sim 1381 \mathrm{~cm}^{-1}$, separated by approx. $202 \mathrm{~cm}^{-1}$, was consistent with unidentate coordination of the carboxylate group. ${ }^{28}$ Such a bonding mode is also known for magnesium and barium mandelates, although in these cases the $\alpha-\mathrm{OH}$ group does not participate in ligand-metal coordination. ${ }^{29}$ Zirconium K-edge EXAFS spectroscopy (Beamline B18, Diamond Light Source, Fig. S6, ESI $\dagger$ ), detected only $\mathrm{Zr}-\mathrm{O}$ correlations and no $\mathrm{Zr}-\mathrm{Zr}$ correlations, as seen for the zirconium tetramer, in $\mathrm{ZrOCl}_{2} \cdot 8 \mathrm{H}_{2} \mathrm{O}$, for example, implying the presence of isolated zirconium centres in the material.

Reaction at room temperature with stirring resulted in a product that was of inferior crystallinity compared to that made hydrothermally; this has been observed also in the crystallisation of other metal mandelates, such as those of divalent transitionmetal cations. ${ }^{30}$ Even for the most crystalline sample, scanning electron microscopy showed the material to be made up of submicron-sized crystallites (Fig. S5, ESI $\dagger$ ), which were not suitable for single crystal diffraction studies. High-resolution X-ray powder diffraction data were measured from a capillary-mounted sample of zirconium mandelate (Beamline I11, Diamond Light Source) and a model for the crystal structure of the material was determined (see ESI $\dagger$ ). Successive improvements to structural models were aided by NMR crystallography, ${ }^{31,32}$ whereby measured spectra were compared to those calculated from the model structure. Adjustment of torsional angles within the ligands and $\mathrm{Zr}-\mathrm{C}$ distances was made to give the best possible match between

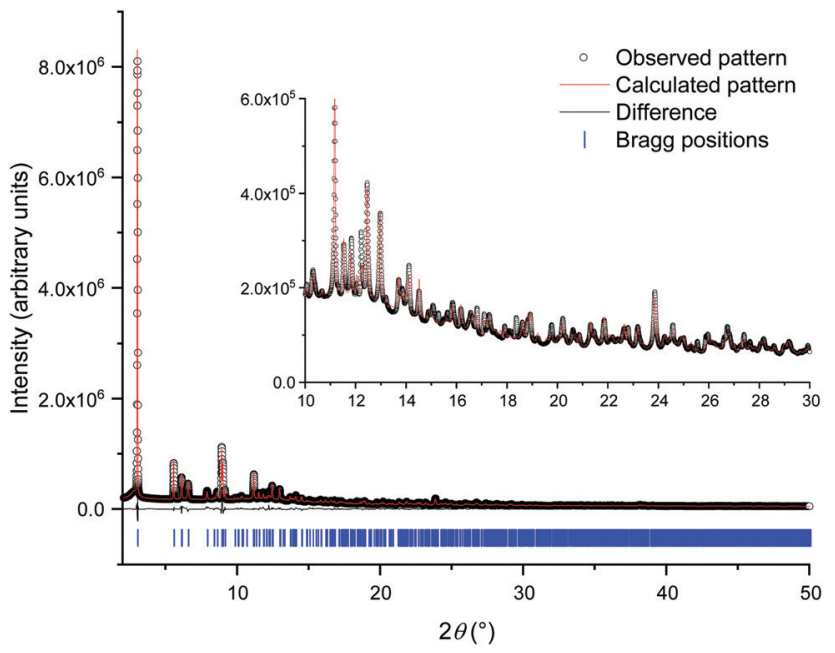

Fig. 1 Final Rietveld fit to the PXRD data. The open circles are the measured data, the red line the fit and the black line the difference curve. The blue ticks show the position of allowed Bragg peaks.

experimental and gauge-including projector augmented wave $(\text { GIPAW })^{33}$ calculated NMR spectra, and consistency with powder diffraction data (see ESI $\dagger$ ). Fig. 1 shows the Rietveld fit to the powder XRD data, Table 1 the crystal structure parameters, and Fig. 2 the ${ }^{1} \mathrm{H} \&{ }^{13} \mathrm{C}$ cross polarisation (CP) magic-angle spinning (MAS) NMR spectra with the GIPAW calculated peak positions from the final crystal structure model. Not seen by PXRD directly was the location of the $\alpha-\mathrm{OH}$ hydrogen atom, inferred from IR spectroscopy, the presence of which was confirmed by ${ }^{1} \mathrm{H}$ NMR (Fig. 2). It was located by considering the possibility of hydrogen bond formation between $\alpha-\mathrm{OH}$ groups and $\mathrm{C}=\mathrm{O}$ groups on neighbouring complexes in the unit cell.

The crystal structure shows the presence of isolated zirconium centres coordinated by two oxygen donor atoms from each of the four mandelates (Fig. 3a). Each of the mandelate ligands is bonded via the oxygen of the $\alpha$-hydroxy group and by one of the carboxylate oxygens. The second carboxylate oxygen is terminal. Upon inspection

Table 1 Crystallographic data of $\mathrm{Zr}\left(\mathrm{C}_{6} \mathrm{H}_{5} \mathrm{CH}(\mathrm{OH}) \mathrm{CO}_{2} \mathrm{H}\right)_{4}$

Crystal structure determined from

CCDC

$M_{\mathrm{w}} / \mathrm{g} \mathrm{mol}^{-1}$

Crystal system

Space group (no.)

$a / \AA$

$b / \AA$

$c / \AA$

$\beta\left({ }^{\circ}\right)$

$V / \AA$

$\rho_{\text {calc }} / \mathrm{mg} \mathrm{m}^{-3}$

$T / \mathrm{K}$

Radiation type

$\lambda / \AA$

$2 \theta$ range $/^{\circ}$

$R_{\mathrm{p}} / \%$

$R_{\mathrm{wp}} / \%$

$R_{\mathrm{B}} / \%$

$\mathrm{GoF}$
Powder data

2004875

695.78

Monoclinic

Pc (7)

17.0775(7)

$5.63423(10)$

16.9860(4)

114.885(3)

1482.62(8)

2

1.558

298

Synchrotron

0.82445

2-50

3.5

4.9

1.7

17 

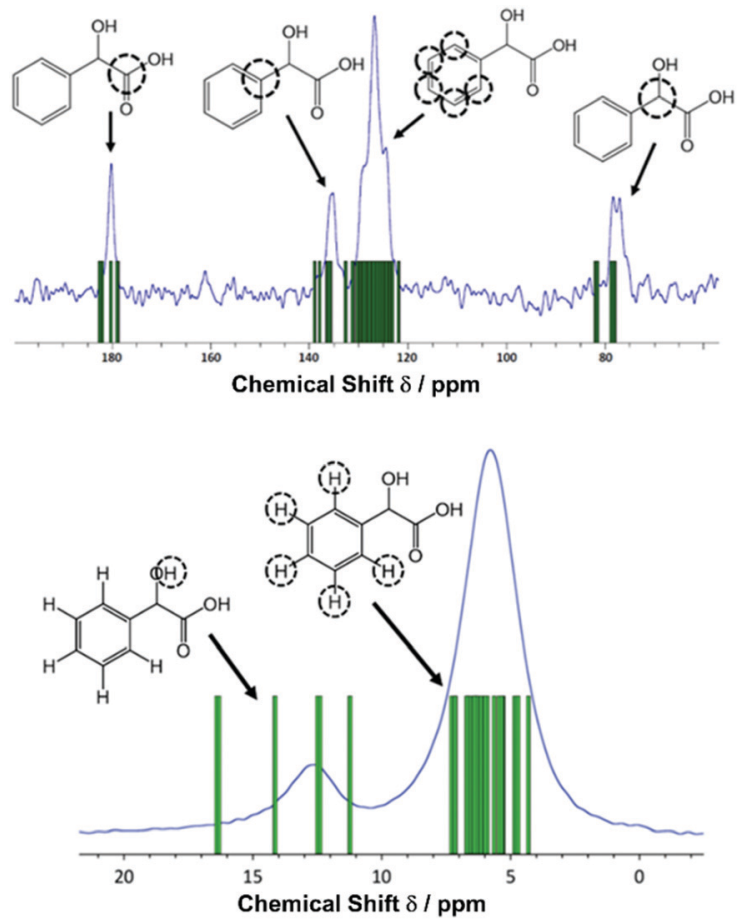

Fig. 2 Solid-state NMR spectra $\left(\nu_{0}\left({ }^{1} H\right)=600 \mathrm{MHz}\right)$ of zirconium mandelate with assignments: top: ${ }^{1} \mathrm{H}-{ }^{13} \mathrm{C} \mathrm{CP} \mathrm{MAS}\left(\nu_{\mathrm{R}}=12.5 \mathrm{kHz}\right.$, contact time $=1.5 \mathrm{~ms}$, $16 \mathrm{co}$-added transients for a recycle delay of $60 \mathrm{~s}$ ). Bottom: ${ }^{1} \mathrm{H}$ one-pulse $\left(\nu_{\mathrm{R}}=60 \mathrm{kHz}, 4 \mathrm{co}\right.$-added transients for a recycle delay of $\left.103 \mathrm{~s}\right)$. The experimental data (blue plots) are overlaid with GIPAW calculated chemical shifts (green bars). The noticeable discrepancies for the $\alpha-\mathrm{OH}$ protons is attributed to the close proximity of these to the zirconium cation.

of the unit cell, it can be seen that one of the two zirconium centres is coordinated by only $(R)$-mandelate, and the other only $(S)$ mandelate ligands (Fig. 3b). Thus, racemisation of mandelic acid must take place in solution during the course of the reaction, as only $(R)$-mandelic acid (or $(S)$-) was used as a precursor, yet both stereochemical forms are present in the final product. Powder X-ray diffraction patterns of the obtained solids showed that the same material was produced regardless of whether the $R$ or $S$ form of mandelic acid was used in the synthesis (Fig. S1, ESI $\dagger$ ).

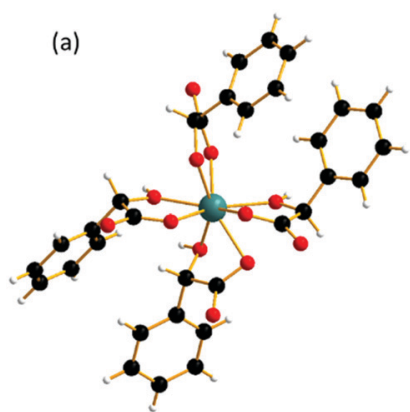

(b)

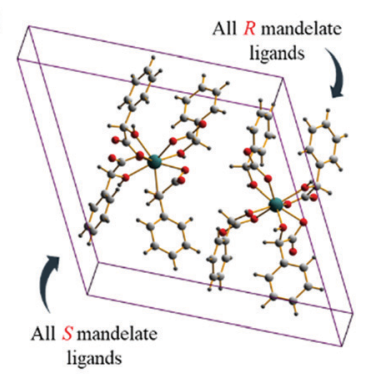

Fig. 3 (a) View of the four mandelate ligands around each zirconium atom. The zirconium centre is coloured turquoise, with oxygen, hydrogen, and carbon atoms in red, white, and black, respectively. (b) A single unit cell of zirconium mandelate, with the different stereochemical forms of the mandelate ligands on each of the zirconium centres indicated.
Mandelic acid is known to racemise readily in both acidic and basic solution, ${ }^{34}$ and the occurrence of this during synthesis of mandelate-containing materials to generate both stereochemical forms in the final product has been seen previously in mandelates of manganese, iron, cobalt, nickel and copper. ${ }^{30}$ In these compounds, which have layered structures, each metal(II) cation is surrounded by six oxygen atoms, four of which arise from two mandelates that both coordinate via the $\alpha-\mathrm{OH}$ oxygen and a carboxylate oxygen. The remaining two oxygen atoms arise from the coordination of a further two mandelate ligands (each via a carboxylate oxygen), both of which bridge to other metal centres (Fig. 4a). A number of other metal mandelates are also known, including zinc and beryllium mandelate, ${ }^{35}$ neodymium mandelate, ${ }^{36}$ gadolinium, terbium, dysprosium and erbium mandelate, ${ }^{37}$ europium mandelate ${ }^{38}$ and rhodium mandelates. ${ }^{39}$ Coordination through both the carboxylate and $\alpha$-hydroxy groups is common amongst these, and the mandelate may also bridge two metal centres, see for example Fig. 4b. A few structures are known for materials featuring a combination of mandelate and other ligands, and these contain similar bonding motifs for mandelate, for example in complexes of $\mathrm{Cu}^{2+}$ (Fig. $4 \mathrm{c}$ and d). ${ }^{40,41}$

In summary, we have demonstrated that with a strongly chelating ligand it is possible to avoid the hydrolysis of zirconium in aqueous solution, which would otherwise occur so readily leading to zirconium oxyclusters in the solid state. To our knowledge, complexes that contain isolated $\mathrm{Zr}$ centres have rarely been reported. In solution, EXAFS has been used to detect the existence of monomeric carbonate complexes under specific concentrations, ${ }^{42,43}$ and potassium salts of zirconium malonate and of zirconium 2,6-dicarboxypicolinate (the latter also containing a nitrogen donor) have been reported, where the monomeric zirconium complexes are separated by the additional cation. ${ }^{44}$ Our results suggest there is more to learn about the aqueous chemistry of zirconium and that with ligand design, novel coordination complexes and networks may be possible.

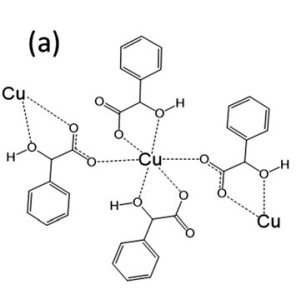

(c)

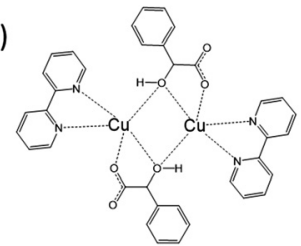

(b)

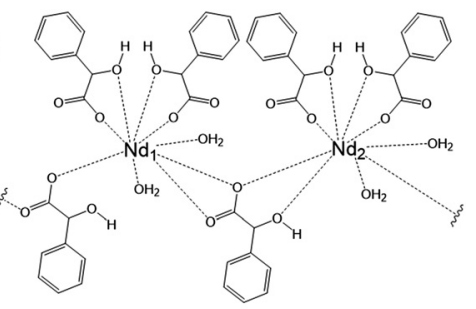

(d)

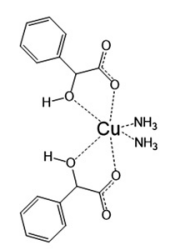

Fig. 4 Examples of the coordination of mandelate in the solid state. (a) The arrangement of mandelate ligands around $\mathrm{Cu}(I)$ as described by Beghidja et al. ${ }^{30}$ (b) A schematic of the repeat unit of the layered structure of neodymium mandelate $^{36}$ (c) The dinuclear $\mathrm{Cu}$ complex $[\mathrm{Cu}(\mathrm{bpy})(\text { mandelate })]_{2} \cdot 8 \mathrm{H}_{2} \mathrm{O} .{ }^{41}$ (d) The mononuclear Cu mandelate complex $\mathrm{Cu}(\text { mandelate })_{2}\left(\mathrm{NH}_{3}\right)_{2} \cdot{ }^{40}$ 
JMC thanks MEL Luxfer Technologies for award of a $\mathrm{PhD}$ studentship. We thank Diamond Light Source for access to diffraction and EXAFS beamlines, and the University of Warwick's Research Technology Platforms. The I11 beamtime was obtained through the Diamond Light Source Block Allocation Group award "Oxford/Warwick Solid State Chemistry BAG to probe composition-structure-property relationships in solids" (EE18786). We also thank Lu Jia for collection of HRPXRD data and Ehsan Ghadim for SEM imaging. EKC thanks EPSRC, AstraZeneca and Syngenta for a PhD studentship through the EPSRC Centre for Doctoral Training in Molecular Analytical Science, grant number EP/L015307/1. The research data underpinning this article can be accessed at: http://wrap.warwick.ac.uk/138907.

\section{Conflicts of interest}

There are no conflicts to declare.

\section{Notes and references}

1 C. A. Kumins, Anal. Chem., 1947, 19, 376-377.

2 D. E. Green, Anal. Chem., 1948, 20, 370-372.

3 J. F. Flagg, H. A. Liebhafsky and E. H. Winslow, J. Am. Chem. Soc., 1949, 71, 3630-3632.

4 W. W. Wendlandt, Anal. Chim. Acta, 1957, 16, 129-134.

5 W.M. Thornton and E. M. Hayden, Z. Anorg. Chem., 1914, 89, 377-382.

6 R. Belcher, A. Sykes and J. C. Tatlow, Anal. Chim. Acta, 1954, 10, 34-47.

7 R. S. Barbieri, V. R. Terra, A. M. Netto and J. C. Rocha, Quim. Nova, 1995, 18, 40-43.

8 A. A. Astanina and E. A. Ostroumov, Chem. Abstr., 1951, 45, 6121.

9 A. A. Astanina and E. A. Ostroumov, Zh. Anal. Khim., 1951, 6, 27-33. 10 R. B. Hahn, Anal. Chem., 1949, 21, 1579-1580.

11 F. Feigl, Chemistry of Specific, Sensitive, and Selective Reactions, Academic Press Inc., New York, 1949.

12 R. B. Hahn and L. Weber, J. Am. Chem. Soc., 1955, 77, 4777-4779.

13 R. B. Hahn and E. S. Baginski, Anal. Chim. Acta, 1956, 14, 45-47.

14 R. N. Kapoor and R. C. Mehrotra, J. Am. Chem. Soc., 1958, 80, 3569-3573. 15 E. M. Larsen and E. H. Homeier, Inorg. Chem., 1972, 11, 2687-2692. 16 A. S. Solovkin and S. V. Tsvetkova, Russ. Chem. Rev., 1962, 31, 655-669. 17 A. Clearfield and P. A. Vaughan, Acta Crystallogr., 1956, 9, 555-558. 18 G. M. Muha and P. A. Vaughan, J. Chem. Phys., 1960, 33, 194-199.
19 J. H. Cavka, S. Jakobsen, U. Olsbye, N. Guillou, C. Lamberti, S. Bordiga and K. P. Lillerud, J. Am. Chem. Soc., 2008, 130, 13850-13851.

20 C. Hennig, S. Weiss, W. Kraus, J. Kretzschmar and A. C. Sheinhost, Inorg. Chem., 2017, 56, 2473-2480.

21 C. Artner, M. Czakler and U. Schubert, Inorg. Chim. Acta, 2015, 432, 208-212.

22 J. Singer and D. T. Cromer, Acta Crystallogr., 1959, 12, 719-723.

23 D. B. McWhan and G. Lundgren, Inorg. Chem., 1966, 5, 284-289.

24 P. Benard, M. Louer and D. Louer, J. Solid State Chem., 1991, 94, 27-35.

25 V. Guillerm, F. Ragon, M. Dan-Hardi, T. Devic, M. Vishnuvarthan, B. Campo, A. Vimont, G. Clet, Q. Yang, G. Maurin, G. Férey, A. Vittadini, S. Gross and C. Serre, Angew. Chem., Int. Ed., 2012, 51, 9267-9271.

26 Y. Bai, Y. Dou, L.-H. Xie, W. Rutledge, J.-R. Li and H.-C. Zhou, Chem. Soc. Rev., 2016, 45, 2327-2367.

27 H. M. Badawi and W. Forner, Spectrochim. Acta, Part A, 2011, 78, 1162-1167.

28 N. Nakamoto, Infrared and Raman Spectra of Inorganic and Coordination Compounds, John Wiley \& Sons, New York, 4th edn, 1986.

29 R. C. Silva, F. J. Caires, D. J. C. Gomes, T. A. D. Colman and M. Ionashiro, J. Therm. Anal. Calorim., 2014, 117, 217-221.

30 A. Beghidja, S. Hallynck, R. Welter and P. Rabu, Eur. J. Inorg. Chem., 2005, 662-669.

31 P. Hodgkinson, Prog. Nucl. Magn. Reson. Spectrosc., 2020, 118-119, 10-53.

32 S. E. Ashbrook and D. McKay, Chem. Commun., 2016, 52, 7186-7204.

33 C. J. Pickard and F. Mauri, Phys. Rev. B: Condens. Matter Mater. Phys., 2001, 63, 245101.

34 A. N. Campbell and A. J. R. Campbell, J. Am. Chem. Soc., 1932, 54, $4581-4585$

35 P. V. Khadikar, R. L. Ameria, M. G. Kekre and S. D. Chauhan, J. Inorg. Nucl. Chem., 1973, 35, 4301-4304.

36 M. Babij, P. Starynowicz and A. Mondry, J. Mol. Struct., 2011, 1006, 672-677.

37 M. Babij and A. Mondry, Opt. Mater., 2012, 34, 2061-2065.

38 M. Babij and A. Mondry, J. Rare Earths, 2011, 29, 1188-1191.

39 F. Pruchnik, B. R. James and P. Kvintovics, Can. J. Chem., 1986, 64, 936-939.

40 H.-Q. Hao, W.-T. Liu, W. Tan, Z.-J. Lin and M.-L. Tong, CrystEngComm, 2009, 11, 967-971.

41 S. Balboa, R. Carballo, A. Castineiras, J. M. Gonzalez-Perez and J. Niclos-Gutierrez, Polyhedron, 2008, 27, 2921-2930.

42 F. Takasaki, K. Fujiwara, Y. Nakajima, T. Nishikawa, H. Masu, M. Imanari, Y. Hidaka and N. Ogawa, Dalton Trans., 2015, 44, 645-652.

43 F. Takasaki, K. Fujiwara, T. Kikuchi, T. Tanno, Y. Nakajima, Y. Toyoda and N. Ogawa, Anal. Sci., 2017, 33, 1007-1012.

44 G. R. Willey, T. J. Woodman, M. Fisher and M. G. B. Drew, Transition Met. Chem., 1998, 23, 467-471. 